\title{
Segregation Analysis of Canine Hip Dysplasia in Cane Corso Italiano Dogs
}

\author{
Korec E*, Hančl M, Bydžovská M, Chalupa 0, Korcová J \\ Department of Genetics, ZOO Tábor, Czech Republic
}

*Corresponding author: Evžen Korec, Department of Genetics, ZOO Tábor, Dukelských hrdinů 19, Prague 7, 17000, Czech Republic

Submission: 眥January 01, 2018; Published: 温January 12, 2018

\begin{abstract}
Segregation analysis of canine hip dysplasia (CHD) was studied for the first time in Cane Corso Italiano dogs. Data was obtained from 1813 dogs, using the Cane Corso Italiano Pedigree Database (www.canecorsopedigree.com).

Federation Cynologique Internationale (FCI) official guidelines were used for scoring the CHD. Offspring segregation of CHD from parental crosses containing combinations of parents' CHD between CHD score A, B and C were analyzed. Results are summarized in Figure 2-7. Offspring segregation of crossing (male A x female B) was compared with the reciprocal crossing (male B x female A). Genes responsible for CHD are probably located on autosomes, therefore reciprocal crossing gave the same results.

Most (59.9 \%) of CHD-A scored offspring arose from male CHD-A x female CHD-A crosses. $50.0 \%$ CHD-A scored offspring arose from the male CHD-A x female CHD-B crosses, and 47.1\% CHD-A scored offspring arose from the male CHD-A x female CHD-C crosses. Only 35.3\% CHD-A scored offspring arose from the male CHD-B x female CHD-B crosses, and 16.7\% CHD-A scored offspring arose from male CHD-C x female CHD-C crosses. Surprisingly, crosses between one parent CHD-A scored and second parent CHD-C scored enabled substantially more CHD-A scored offspring, compared to crosses of both parents CHD-B scored.

These results suggest that an optimal Cane Corso Italiano breeding programme for reducing CHD should employ crosses of males and females, both CHD-A scored. Cane Corso Italiano breeders should realize regularly crosses of both parents CHD-A scored, rarely crosses of one parent CHD-A scored and second CHD-B scored, exceptionally crosses of one parent CHD-A scored and second CHD-C scored. Responsible breeders should exclude any crosses of both parents worse than CHD-A scored. The main pedigreed breeding males should be only CHD-A scored.
\end{abstract}

Keywords: Canine hip dysplasia; Cane corso italiano; Breeding programme; Hip scores; Selective breeding

Abbreviations: CHD: Canine Hip Dysplasia; FCI: Federation Cynologique Internationale; OFA: Orthopaedic Foundation for Animals; EBV: Estimated Breeding Values

\section{Introduction}

Canine hip dysplasia affects dogs of all breeds, and is the most frequent orthopaedic disease in large and giant breed dogs. Radiology has commonly been used for diagnosis of CHD. Three somewhat different international scoring methods were developed. The Federation Cynologique Internationale (FCI), the Orthopaedic Foundation for Animals (OFA), and the British Veterinary Association/Kennel Club (BVA/KC) methods. Details of 3 different scoring systems were described by Flückiger [1]. The FCI scoring method is used in member countries of FCI (most European countries, Russia, South America, and Asia), the OFA method is used exclusively in USA and Canada, and the BVA/KC method is used in Great Britain, Ireland, New Zealand, and Australia.

In consequence of the major progress in the detection of genes responsible for CHD [2-7], many investigators have suggested the implementation of estimated breeding values (EBV) to improve the selection [8-13]. Phenotypic screening of joint conformation remains a currently available strategy for breeders to make selection decisions. The present study [14] showed the efficiency of employing phenotypic selection on breed improvement of CHD and canine elbow dysplasia in 60 dog breeds. A similar effect of phenotypic selection was described in the past $[15,16]$. The Cane Corso Italiano (Figure 1) is a new dog breed that was fully recognized by FCI in 2007. Results of the first investigation of this breed were described by Korec et al. [17]. The current paper describes for the first time the Cane Corso Italiano segregation analysis of CHD, and suggests a simple method that can be used by breeders for selection, that would enable a reduction in the prevalence of CHD in offspring.

\section{Materials and Methods}

\section{Data collection}

Data was obtained from 1813 CHD scored dogs, using the Cane Corso Italiano Pedigree Database (www.canecorsopedigree.com). FCI official guidelines were used for scoring CHD. 


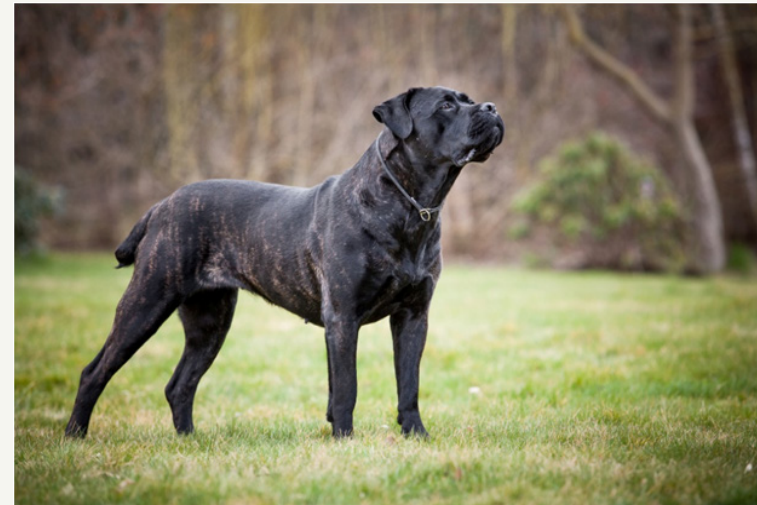

Figure 1: Photograph of a Cane Corso Italiano dog (Koleta Atison, Evžen Korec's archive).

\section{Results and Discussion}

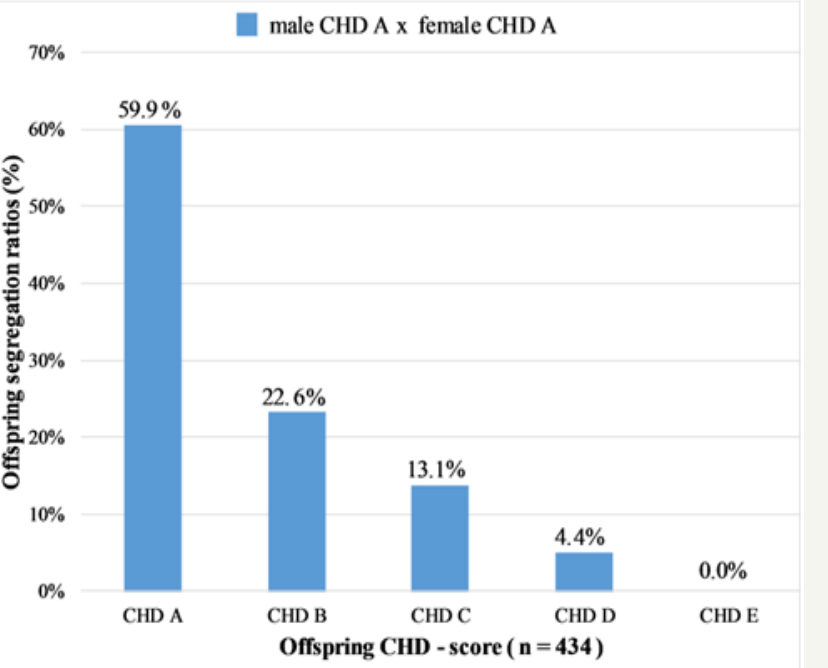

Figure 2: Parental crosses male CHD-A x female CHD-A.

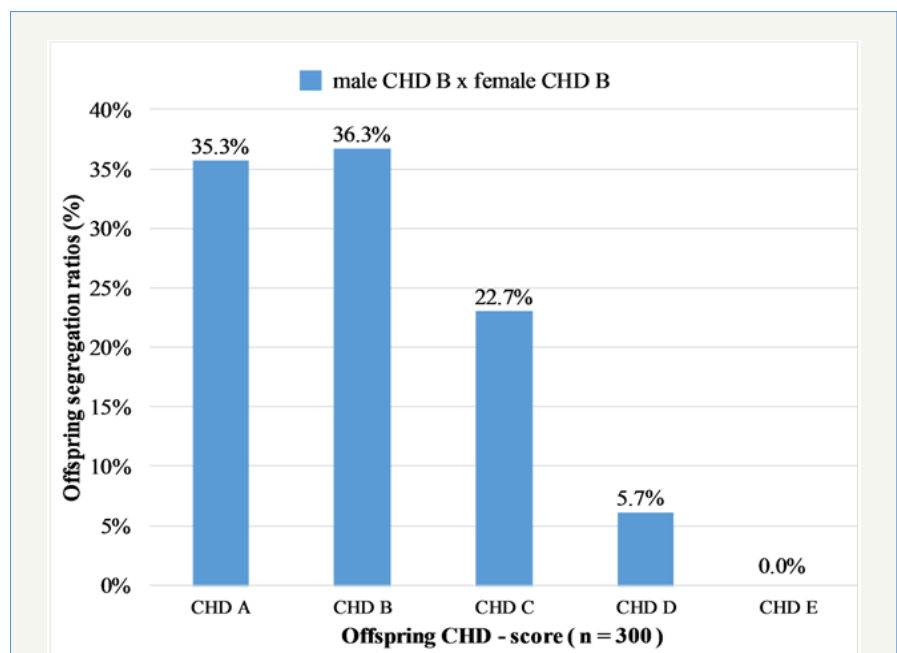

Figure 3: Parental crosses male CHD-B x female CHD-B.

Offspring segregation of CHD from parental crosses containing parents' CHD combinations between CHD scored A, B, and C were analyzed. Results are summarized in Figure 2-7. Offspring segregation of parental crossing (male $\mathrm{A} x$ female $\mathrm{B}$ ) was compared with reciprocal crossing (male $\mathrm{B} x$ female $\mathrm{A}$ ).

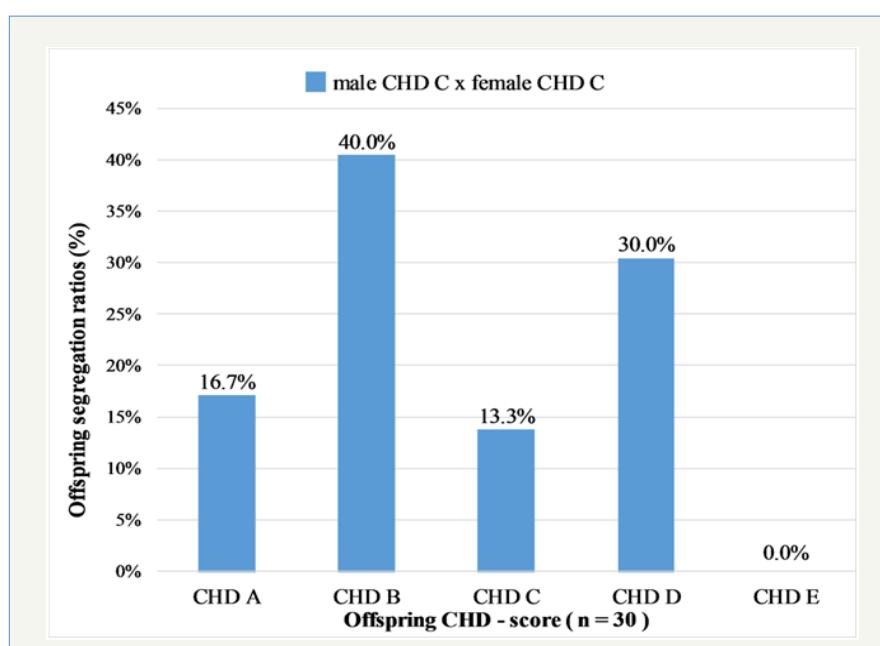

Figure 4: Parental crosses male CHD-C x female CHD-C.

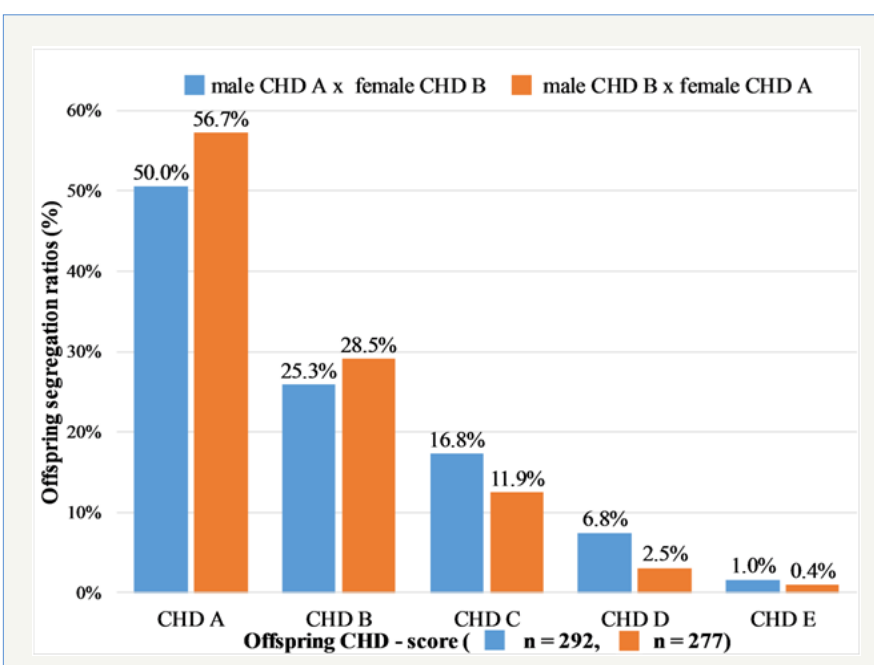

Figure 5: Parental crosses male CHD-A x female CHD-B, male CHD-B x female CHD-A.

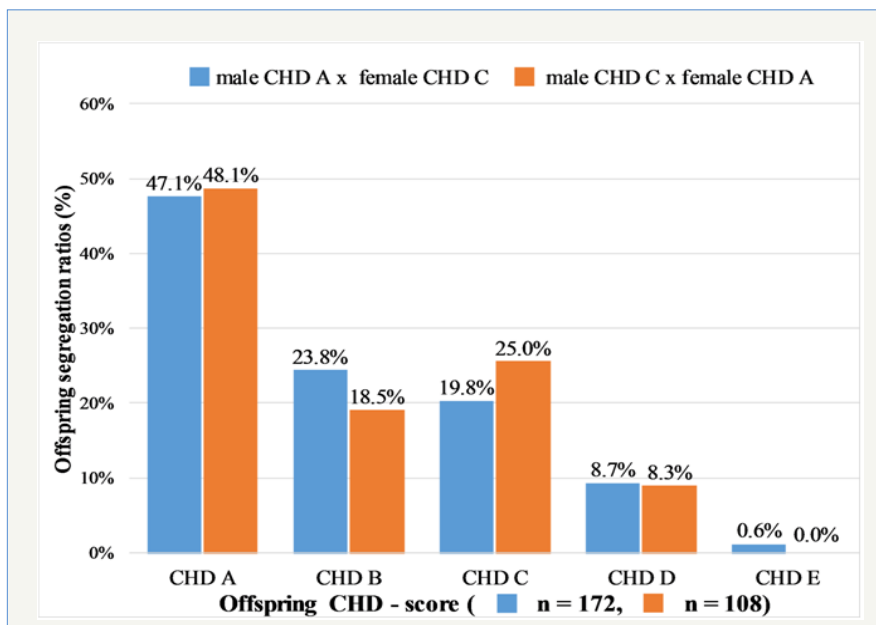

Figure 6: Parental crosses male CHD-A x female CHD-C, male CHD-C x female CHD-A. 


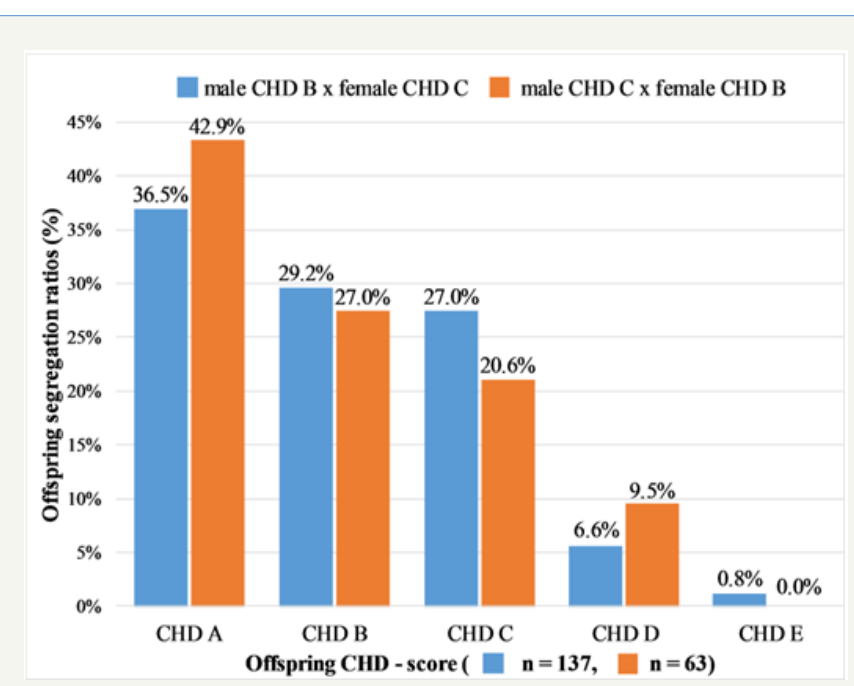

Figure 7: Parental crosses male CHD-B x female CHD-C, male CHD-C x female CHD-B.

Most (59.9\%) of CHD-A scored offspring arose from male CHD-A $x$ female CHD-A crosses, $50.0 \%$ CHD-A offspring arose from male CHD-A $x$ female CHD-B crosses, and $47.1 \%$ CHD-A offspring arose from male CHD-A x female CHD-C. Only $35.3 \%$ CHD-A offspring arose from male CHD-B $x$ female CHD-B crosses, and 16.7\% CHD-A scored offspring arose from male CHD-C x female CHD-C crosses. Interesting, and for breeders valuable, is our finding that male CHD-A $x$ female CHD-C crosses or reciprocal crosses of male CHD-C $x$ female CHD-A enable substantially more CHD-A scored offspring, compared to male CHD-B $\mathrm{x}$ female CHD-B crosses.

These results suggest that some dominant gene or genes are responsible for the CHD-A phenotype. Reciprocal crosses gave approximately same offspring segregation of CHD. Minor differences are probably caused by the fact that also environmental (not only genetics) factors influence the CHD-score. The genes responsible for the CHD-status are probably located on the autosomes. Our results suggest that the optimal breeding programme for the reduction of the prevalence of CHD should employ crosses of males and females that are both CHD-A scored. Breeders should regularly realize these crosses, rarely crosses of one parent CHD-A scored and second CHD-B scored, and exceptionally crosses of one parent CHD-A scored and second CHD-C scored. Responsible breeders should exclude all crosses of both parents worse than CHD-A scored. The main pedigreed breeding males should only be CHD-A scored.

\section{References}

1. Flückiger M (2007) Scoring radiographs for canine Hip Dysplasia-The big three organisations in the World. Eur J Companion Anim Pract 17: 135-140.
2. Chase K, Lawler DF, Adler FR, Ostrander EA, Lark KG (2004) Bilaterally asymmetric effects of quantitative trait loci (QTLs): QTLs that affect laxity in the right versus left coxofemoral (hip) joints of the dog (Canis familiaris). Am J Med Genet A 124A(3): 239-247.

3. Sutter NB, Ostrander EA (2004) Dog star rising: the canine genetic system. Nat Rev Genet 5(12): 900-910.

4. Chase K, Lawler DF, Carrier DR, Lark KG (2005) Genetic regulation of osteoarthritis: A QTL regulating cranial and caudal acetabular osteophyte formation in the hip joint of the dog (Canis familiaris). Am J Med Genet A 135(3): 334-335.

5. Lindblad TK, Wade CM, Mikkelsen TS, Karlsson EK, Jaffe DB, et al. (2005) Genome sequence, comparative analysis and haplotype structure of the domestic dog. Nature 438(7069): 803-819.

6. Sutter NB, Bustamante CD, Chase K, Gray MM, Zhao K, et al. (2007) A single IGF1 allele is a major determinant of small size in dogs. Science 316(5821): 112-115.

7. Zhu L, Zhang Z, Friedenberg S, Jung SW, Phavaphutanon J, et al. (2009) The long (and winding) road to gene discovery for canine hip dysplasia. Vet J 181(2): 97-110.

8. Leighton EA (1997) Genetics of canine hip dysplasia. J Am Vet Med Assoc 210(10): 1474-1479.

9. Wilson B, Nicholas FW, Thomson PC (2011) Selection against canine hip dysplasia: success or failure? Vet J 189(2): 160-168.

10. Hou Y, Wang Y, Lu X, Zhang X, Zhao Q, et al. (2013) Monitoring Hip and Elbow Dysplasia achieved modest genetic improvement of 74 dog breeds over 40 years in USA. PLoS One 8(10): e76390.

11. Lewis TW, Blott SC, Woolliams JA (2013) Comparative analyses of genetic trends and prospects for selection against hip and elbow dysplasia in 15 UK dog breeds. BMC Genet 14: 16.

12. Sánchez-ME, Woolliams JA, Pong-WR, Clements DN, Blott SC, et al. (2014) Quantitative trait loci mapping for canine hip dysplasia and its related traits in UK Labrador Retrievers. BMC Genomics 15: p. 883.

13. Soo M, Worth A (2015) Canine hip dysplasia: phenotypic scoring and the role of estimated breeding value analysis. N Z Vet J 63(2): 69-78.

14. Oberbauer AM, Keller GG, Famula TR (2017) Long-term genetic selection reduced prevalence of hip and elbow dysplasia in 60 dog breeds. PLoS One 12(2): e0172918.

15. Janutta V, Hamann H, Distl O (2008) Genetic and phenotypic trends in canine hip dysplasia in the German population of German shepherd dogs. Berl Munch Tierarztl Wochenschr 121(3-4): 102-109.

16. Keller GG, Dziuk E, Bell JS (2011) How the Orthopedic Foundation for Animals (OFA) is tackling inherited disorders in the USA: using hip and elbow dysplasia as examples. Vet J 189(2): 197-202.

17. Korec E, Chalupa O, Hančl M, Korcová J, Bydžovská M (2017) Longevity of Cane Corso Italiano dog breed and its relationship with hair colour. Open Vet J 7(2): 170-173. 